\title{
Dampak Faktor Internal dan Eksternal Terhadap Harga Saham Sektor Infrastruktur
}

\author{
Bonita Restu Dwijayati ${ }^{*}$, Robiyanto ${ }^{2}$ \\ 1,2 Fakultas Ekonomika dan Bisnis Manajemen, Universitas Kristen Satya Wacana, Salatiga, Jawa Tengah
}

\section{A R T I C L E I N F O}

Article history:

Received 01 December 2019

Received in revised form

31 December 2019

Accepted 15 January 2020

Available online 26

February 2020

\section{Kata Kunci:}

DPR, NPM, CCC, Suku Bunga

dan Harga Saham

Keywords:

DPR, NPM, CCC, Interest

Rates and Stock Price

\begin{abstract}
A B S T R A K
Penelitian ini bertujuan untuk menguji dampak faktor internal dan eksternal baik secara simultan maupun parsial terhadap harga saham sektor infrastruktur, utilitas, dan Transportasi. Penelitian menggunakan metode kuantitatif. Populasi dalam penelitian ini adalah seluruh perusahaan infrastruktur, utilitas dan transportasi yang terdaftar di Bursa Efek Indonesia pada periode 2014-2018. Teknik pemilihan sampel yaitu dengan menggunakan metode purposive sampling. Berdasarkan kriteria yang telah ditentukan, diperoleh 30 perusahaan yang menjadi sampel. Teknik analisis data menggunakan analisis regresi data panel. Hasil penelitian menunjukkan bahwa secara simultan variabel DPR, NPM, CCC dan Suku Bunga berpengaruh signifikan terhadap Harga Saham sektor infrastruktur. Sedangkan secara parsial, variabel DPR dan NPM berpengaruh positif tidak signifikan terhadap Harga Saham. Di sisi lain variabel CCC berpengaruh negatif signifikan terhadap Harga Saham dan suku bunga berpengaruh positif signifikan terhadap Harga Saham
\end{abstract}

\section{A B S T R A C T}

This research aims to test the impact of internal and external factors both simultaneously and partially against the stock price of infrastructure sectors. Research using quantitative methods. The population in this study is the entire infrastructure, utilities and transportation company listed on the Indonesia Stock Exchange in the period 2014-2018. The sample selection technique is using the purposive sampling method. Based on predefined criteria, acquired 30 companies are being sampled. Data analysis techniques use a regression analysis of data panels. The results showed that the simultaneous variables of the DPR, NPM, CCC and interest rates had significant effect on the stock price of infrastructure sectors. As for the partial, the variables of the DPR and NPM positively influence insignificant against the stock price. On the other hand the CCC variables have significant negative effect on the stock price and the interest rate is significantly positive against the stock price.

\footnotetext{
* Corresponding author.

E-mail addresses: bonitadwijayati@gmail.com (Bonita Restu Dwijayati)
} 


\section{Pendahuluan}

Keberadaan Infrastruktur merupakan segala fasilitas penunjang baik fisik maupun non fisik yang berguna untuk melayani masyarakat dan mendukung pertumbuhan ekonomi (Baidarus, Nimas Ayu Anggraeni, \& Zafira Mauliza, 2018). Badan Koordinasi Penanaman Modal, (2019) menjelaskan indeks sektor infrastruktur, utilitas dan transportasi selama year to date naik 12,47 persen. Hal ini didukung oleh subsektor telekomunikasi yang berkontribusi 62,3 persen dan subsektor transportasi 12,1 persen. Peningkatan kinerja perusahaan akan mempengaruhi laba pada perusahaan, sehingga hal itu akan berdampak terhadap harga saham. Peningkatan dipengaruhi oleh faktor internal dan eksternal perusahaan (Kembaren et al., 2019).

Hasil penelitian milik Khan, (2012) menjelaskan bahwa dividen berpengaruh positif signifikan terhadap harga saham. Sedangkan penelitian lain Al Masum, (2014) berpendapat dividen berpengaruh negatif dan tidak signifikan terhadap harga saham. Faktor internal lain yang mempengaruhi harga saham adalah Net Profit Margin dan Cash Conversion Cycle. Penelitian milik Rahmat \& Dewi, (2014), Pitriana, (2017), Öztürk \& Karabulut, (2017) dan Istiqomah \& Winarto, (2017) membuktikan NPM berpengaruh positif signifikan terhadap harga saham. Sedangkan, penelitian milik Ramadhana et al., (2018) mendapat hasil, NPM memiliki pengaruh positif tidak signifikan terhadap harga saham. Wiyono, (2017) membuktikan bahwa CCC memiliki pengaruh negatif signifikan terhadap Price Earning Ratio dimana hal tersebut akan berpengaruh negatif signifikan juga terhadap harga saham. Penelitian lain menjelaskan CCC tidak memiliki pengaruh terhadap profitabilitas, sehingga nantinya tidak ada pengaruh terhadap harga saham (Mbawuni et al., 2016).

Hughen \& Beyer, (2015) menyatakan selain dividen, NPM dan CCC, harga saham juga dapat dipengaruhi oleh faktor eksternal seperti suku bunga. Nurlina, (2017) memberi bukti bahwa suku bunga berpengaruh positif signifikan terhadap harga saham. Penelitian tersebut sejalan dengan Iba \& Wardhana, (2012) yang juga menjelaskan bahwa suku bunga berpengaruh terhadap harga saham. Sedangkan penelitian milik Widiastuti et al., (2016) menjelaskan suku bunga tidak berpengaruh terhadap harga saham.

Kebanyakan penelitian lain berfokus pada rasio likuiditas, solvabilitas, profitabilitas dan rasio pasar dikarenakan berkaitan langsung terhadap investor yang akan membeli saham, padahal rasio aktivitas seperti CCC memiliki keunggulan yaitu mengubah investasi menjadi uang tunai, yang berguna untuk memudahkan perusahaan membagi waktu guna membayar hutang-hutang serta menjadi aliran sumber keuangan yang berguna bagi persediaan perusahaan, sehingga hal ini akan mempengaruhi kinerja dan harga saham perusahaan kedepannya. Oleh karena itu penelitian ini dilakukan, menggunakan rasio aktivitas yaitu CCC sebagai variabel bebas. Sehingga dapat dirumuskan permasalahan sebagai berikut : saham?

Apakah faktor internal dan eksternal berpengaruh secara simultan dan parsial terhadap harga

Tujuan dalam penelitian ini menjelaskan dampak secara simultan dan parsial faktor internal dan eksternal terhadap harga saham. Sedangkan manfaat penelitian menjadi tambahan literatur bagi penelitian selanjutnya serta menjadi bahan masukan bagi perusahaan dalam menganalisis dampak faktor internal dan eksternal terhadap harga saham sektor infrastruktur, utilitas dan transportasi kedepannya.

Faktor fundamental berkaitan langsung dengan kinerja keuangan perusahaan. Faktor internal perusahaan (Faktor fundamental) berupa rasio likuiditas, rasio aktifitas, rasio solvabilitas dan rasio profitabilitas. Faktor internal memiliki risiko masing-masing sehingga, untuk meminimalkan risiko tersebut, seperti pada teori portofolio, Markowitz, (1952) menyebut dengan Diversifikasi, dimana investor disarankan agar berinvestasi tidak hanya pada satu jenis investasi, akan tetapi beberapa jenis investasi agar meminimalisir risiko non sistematis. Dalam teori APT atau Arbitrage Pricing Theory, faktorfaktor yang mempengaruhi harga saham tidak hanya pada internal perusahaan, akan tetapi risiko sistematis pasar seperti suku bunga, inflasi dan kurs juga dapat mempengaruhi harga pasar (Ross, 1976).

Rasio pasar merupakan rasio yang memberikan informasi kepada investor terkait penilaian perusahaan berdasarkan saham yang dimiliki. Rasio pasar yang digunakan adalah DPR. Sesuai dengan teori Bird In Hand, investor bersedia membayar harga yang lebih tinggi untuk perusahaan yang membayar dividen saat ini, karena investor beranggapan bahwa dividen saat ini risikonya lebih kecil daripada capital gain di masa depan. Hal ini dikarenakan dividen tunai merupakan bentuk kepastian yang dapat mengurangi risiko (Lintner, 1962 ; Gordon, 1963).

Teori lain yaitu teori signaling memandang bahwa laporan keuangan adalah sinyal bagi para investor. Melalui laporan keuangan, investor mengetahui informasi mengenai cash dividend yang dibayarkan. Jika kenaikan dividen tinggi daripada yang diharapkan, maka laba perusahaan meningkat hal ini merupakan sinyal baik bagi investor sehingga harga saham juga meningkat (Bhattacharya, 1979). 
Rasio profitabilitas adalah cara perusahaan dalam menghasilkan keuntungan dalam satu periode tertentu melalui modal dan aset yang dimiliki oleh perusahaan. Rasio profitabilitas yang digunakan adalah NPM. NPM merupakan kunci penilaian atas perusahaan, karena digunakan untuk melihat efisiensi terhadap perusahaan itu sendiri. Bayrakdaroglu et al, (2017) mengatakan semakin tinggi rasio NPM menunjukan bahwa semakin baik operasional suatu perusahaan itu sendiri. Hal ini dikarenakan perusahaan mampu mengelola margin laba bersih dengan baik sehingga risiko rendah dan harga saham akan naik (Rahmat \& Dewi, 2014).

Rasio aktivitas adalah rasio yang digunakan untuk melihat efisiensi perusahaan dalam memanfaatkan seluruh aktiva yang dimiliki oleh perusahaan. Rasio aktivitas yang digunakan adalah CCC. Agu (2019) menjelaskan bahwa CCC berupa aset lancar dan kewajiban lancar yang berkaitan erat dengan keberhasilan operasional suatu perusahaan. CCC memiliki pengaruh negatif signifikan terhadap karakter keuangan perusahaan dan Price Earning Ratio (PER). PER berkaitan langsung terhadap harga saham. Sehingga apabila CCC berjalan lebih cepat, maka harga saham perusahaan akan naik. Hal ini dikarenakan pengelolaan CCC yang berjalan secara efisien (Wiyono, 2017).

Widiastuti et al., (2016) menjelaskan bahwa suku bunga merupakan ukuran suatu harga sumber daya yang digunakan oleh debitur yang dibayarkan kepada kreditur. Apabila suku bunga meningkat, para investor menganggap hal ini kurang baik karena risiko yang diterimanya akan tinggi, sehingga mereka cenderung menginvestasikan dananya di bank. Akibatnya harga saham menjadi turun karena biaya yang dikeluarkan perusahaan semakin tinggi, dan investor menjadi kurang berminat.

Berdasarkan teori yang ada, maka hipotesis penelitian ini adalah sebagai berikut:

H1 : Secara Simultan DPR, NPM, CCC dan Suku Bunga berpengaruh signifikan terhadap Harga Saham.

H2 : DPR berpengaruh positif signifikan terhadap Harga Saham.

H3 : NPM berpengaruh positif signifikan terhadap Harga Saham

H4 : CCC berpengaruh negatif signifikan terhadap Harga Saham

H5 : Suku bunga berpengaruh negatif signifikan terhadap Harga Saham

\section{Metode}

Populasi terdiri dari seluruh perusahaan Infrastruktur, Utilitas, dan Transportasi yang terdaftar di Bursa Efek Indonesia (BEI) tahun 2014 - 2018. Metode penentuan sampel menggunakan purposive sampling. Melalui kriteria yaitu masuk dalam perusahaan sektor Infrastruktur, Utilitas dan Transportasi tahun 2014-2018, laporan keuangan dan laporan tahunan lengkap, serta informasi lengkap mengenai DPR, NPM, dan CCC didapatkan sampel yaitu 30 perusahaan. Jenis data yang digunakan adalah data kuantitatif. Sumber data yang digunakan adalah data sekunder. Data sekunder diperoleh dari laporan keuangan tahunan perusahaan infrastruktur, utilitas dan transportasi tahun 2014-2018, Indonesia Capital Market Directory (ICMD) 2019, Yahoo Finance, dan BI rate.

Teknik analisis data menggunakan regresi data panel. Langkah awal pengujian yaitu menentukan model estimasi yang tepat, berupa metode common effect model (CEM), fixed effect model (FEM), dan random effect model (REM). CEM atau Pooled Least Square adalah pendekatan data yang hanya mengkombinasikan data time series dan cross section dalam bentuk pool dan menggunakan teknik kuadrat terkecil untuk mengestimasi koefisiennya. Kemudian FEM atau Least Square Dummy Variables (LSDV) adalah model yang menghasilkan intersep konstan untuk setiap individu dan waktu, sehingga perbedaan antar individu dapat diakomodasi dari perbedaan intersepnya. Sedangkan REM yaitu untuk mengatasi ketidakpastian model yang digunakan pada FEM. Di dalam model ini, terdapat dua komponen residual yaitu residual secara menyeluruh, yang merupakan kombinasi time series dan cross section dan residual secara individu yang merupakan karakteristik random dari observasi unit ke-i dan tetap sepanjang waktu. Pengolahan data menggunakan aplikasi Eviews 9.

Tabel 1. Ringkasan operasional variabel dan rumus

\begin{tabular}{llll}
\hline No & Variabel & Pengertian & Rumus \\
\hline 1. & Harga Saham $(\mathrm{Y})$ & Harga yang ditentukan oleh & Rata-rata perbulan dari nilai saham \\
& & penawaran dan permintaan saham & perusahaan saat penutupan (closing \\
& & di pasar modal & price).
\end{tabular}


2. $\operatorname{DPR}(\mathrm{X} 1)$

3. $\mathrm{NPM}(\mathrm{X} 2)$

4. $\mathrm{CCC}(\mathrm{X} 3)$
Rasio antara laba yang dibayarkan dalam bentuk dividen dengan total laba yang tersedia bagi pemegang saham (Wahyuni dan Hafiz, 2016). Satuan nilai penjualan yang tersisa dikurangi seluruh biaya, termasuk pajak dan bunga (Rahmat \& Dewi, 2014)

Bagian dari manajemen modal kerja. Dimana CCC sendiri dapat mempengaruhi profitabilitas dan likuiditas pada perusahaan, karena semakin cepat CCC maka periode yang dibutuhkan untuk mengkonversi kas juga semakin cepat (Setyanto \& Permatasari, 2015).

5. Suku Bunga (X4)
Suku bunga merupakan harga yang dibayarkan atau biaya peminjaman atas dana pinjaman yang dinyatakan dalam bentuk persentase (Suchia,

\section{Dividend perShare \\ Earning per Share $\mathrm{x} 100 \%$}

Net profit / net sales
$\mathrm{CCC}=\mathrm{DSO}+\mathrm{DIO}-\mathrm{DPO}$
$\mathrm{DSO}=$ Days Sales Outstanding
$\frac{\text { Average Account Receivables }}{\text { Sales }}$

DIO= Days Inventory Outstanding

Average Inventory

${ }^{C O G S} \&_{365}$

DPO= Days Payables Outstanding

Average Account Payables ${ }^{C O G S} / 365$

Rata-rata suku bunga per bulan 2018)

Dalam menggunakan regresi data panel, terlebih dahulu lolos uji asumsi klasik. Model regresi data panel pada penelitian ini sebelumnya dipastikan sudah lolos uji asumsi klasik yaitu normalitas, heteroskedastisitas, dan multikolinearitas. Berikut model regresi data panel :

$\begin{array}{ll}Y_{i t}=\alpha+\beta_{1} X_{1 i t}+\beta_{2} X_{2 i t}-\beta_{3} X_{3 i t}-\beta_{4} X_{4 i t} \ldots .+\beta_{n} X_{n i t}+e_{i t} \\ Y & =\text { Harga Saham } \\ a & =\text { Konstanta } \\ \beta_{1}, \beta_{2}, \beta_{3}, \beta_{4}, & =\text { Koefisien regresi } \\ X_{1} & =\text { DPR } \\ X_{2} & =\text { NPM } \\ X_{3} & =\text { CCC } \\ X_{4} & =\text { SUKU BUNGA } \\ i & =\text { entitas ke- } i \\ t & =\text { periode ke- } t \\ e & =\text { random error }\end{array}$

\section{Hasil dan pembahasan}

Tabel2. Statistik deskriptif

\begin{tabular}{llllll}
\hline & HARGA & DPR & NPM & CCC & SUKU BUNGA \\
& SAHAM & & & & \\
\hline Mean & 1042,253 & 13,98313 & $-17,74700$ & 118,9404 & 6,010897 \\
Std. Dev & 1797,330 & 51,22543 & 91,89038 & 82,42629 & 1,110336 \\
N & 150 & 150 & 150 & 150 & 150 \\
\hline
\end{tabular}


Variabel dependen yaitu Harga Saham memiliki nilai mean sebesar 1042,253 dan nilai deviasinya 1797,330 . Sedangkan variabel independen DPR $\left(\mathrm{X}_{1}\right)$ memiliki nilai mean 13,983 dan nilai deviasi sebesar 51,225. Kemudian NPM $\left(X_{2}\right)$ memiliki nilai mean -17,747 dan nilai deviasi 91,890. Variabel dependen yang ketiga yaitu CCC $\left(\mathrm{X}_{3}\right)$ memiliki nilai mean 118,94 sedangkan nilai deviasinya 82,426. Terakhir, Suku Bunga memiliki nilai mean 6,0108 sedangkan nilai deviasinya adalah 1,1103. Dapat disimpulkan bahwa nilai deviasi Harga Saham, DPR dan NPM lebih besar daripada nilai mean. Sedangkan nilai deviasi dari CCC dan Suku Bunga lebih kecil daripada nilai meannya, sehingga data CCC dan Suku Bunga mewakili data yang baik bagi penelitian. Dalam pemilihan model estimasi, model REM yang paling tepat digunakan pada penelitian ini.

\section{Uji Asumsi Klasik}

Uji Normalitas digunakan untuk menguji apakah data berdistribusi normal atau tidak. Apabila nilai Sig. > 0,05 maka data tersebut berdistribusi normal. Dalam penelitian ini, nilai Probabilitas dari JaqueBera adalah 0,00 . Sehingga data tidak normal.

Uji Heterokedastisitas digunakan untuk menguji apakah ada ketidaksamaan varian residual untuk semua pengamatan pada model regresi linier. Jika nilai probabilitas $>0,05$ maka data terbebas dari heteroskedastisitas. Hasil menunjukan bahwa melalui metode Glejser, menghasilkan nilai Prob.F yaitu 0,6642 sehingga data lolos uji heteroskedastisitas.

Uji Multikolinearitas adalah apakah ada hubungan korelasi yang kuat antara dua variabel bebas atau lebih dalam model regresi. Apabila nilai VIF $<10$ atau 5 maka data tersebut terbebas dari multikolinearitas. Di dalam penelitian ini nilai VIF untuk DPR adalah 1,041, Sedangkan NPM nilai VIF adalah 1,033, kemudian CCC nilai VIF adalah 1,043 dan suku bunga nilai VIF adalah 1,049. Sehingga lolos dari multikolinearitas karena nilai VIF kurang dari 10 dan 5.

\section{Pengujian Hipotesis}

Uji F menguji apakah ada pengaruh variabel bebas secara simultan terhadap variabel terikat. Berdasarkan Nilai Signifikansi dari output adalah 0,0034 $<0.05$ persen, sehingga secara simultan DPR,NPM,CCC dan Suku Bunga berpengaruh signifikan terhadap Harga Saham. Selanjutnya, Uji t digunakan untuk melihat apakah secara parsial atau individu variabel bebas mempengaruhi variabel terikat atau tidak. Hasil uji t adalah sebagai berikut :

Tabel 3. Uji t

\begin{tabular}{lllll}
\hline Variable & Coefficient & Std. Error & t-Statistic & Prob. \\
\hline C & 620,5121 & 396,8603 & 1,563553 & 0,1201 \\
DPR & 0,258561 & 0,785149 & 0,329315 & 0,7424 \\
NPM & 0,067991 & 0,416854 & 0,163104 & 0,8707 \\
CCC & $-0,200531$ & 0,606382 & $-1,979827$ & 0,0496 \\
SB & 93,50026 & 30,66671 & 3,048917 & 0,0027 \\
\hline
\end{tabular}

Nilai Sig. variabel DPR sebesar 0,7424 dan nilai Sig. NPM sebesar 0,8707 sehingga kedua variabel tersebut $>0,05$, maka variabel DPR dan NPM tidak berpengaruh signifikan secara parsial terhadap harga saham. Sedangkan variabel bebas CCC memiliki nilai Sig. 0,0496 dan nilai Sig suku bunga adalah 0,0027< 0,05 , sehingga CCC dan suku bunga berpengaruh signifikan secara parsial terhadap harga saham.

3. Pembahasan Hasil Penelitian

Hasil penelitian ini menyatakan bahwa secara simultan variabel DPR, NPM, CCC dan Suku Bunga berpengaruh terhadap Harga Saham. Sehingga H1 diterima. Di sisi lain hasil uji koefisien determinasi Rsquared menunjukkan angka 10,21 persen. Hal ini memiliki arti bahwa Harga Saham dipengaruhi oleh variabel bebas DPR, NPM, CCC dan suku bunga sebesar 10,21 persen dan sisanya 89,79 persen dipengaruhi oleh variabel lain di luar penelitian ini. Harga saham di suatu negara dipengaruhi tidak hanya 
oleh keadaan internal perusahaan di negara tersebut tetapi juga dari eksternal perusahaan yaitu suku bunga.

\section{Pengaruh DPR (Dividend Payout Ratio) terhadap Harga Saham}

Hasil hipotesis kedua secara parsial DPR berpengaruh positif tidak signifikan terhadap Harga Saham. Hal ini dapat dilihat bahwa nilai Prob. Sig. adalah 0,7424>0,05 sehingga H2 ditolak Hasil penelitian ini sesuai dengan penelitian milik Girsang et al., (2019) dan Nwaobia A. et al., (2017). Hal ini dikarenakan sebagian besar perusahaan infrastruktur hanya beberapa perusahaan saja yang mau membagikan dividen kepada investor, walaupun tidak secara rutin. Hasil penelitian tidak sesuai dengan penelitian milik Khan (2012) yang menyatakan bahwa variabel DPR berpengaruh positif signifikan terhadap harga saham secara parsial.

\section{Pengaruh NPM (Net Profit Margin) terhadap Harga Saham}

Pada uji t dapat dilihat bahwa nilai Prob. NPM adalah 0,8707 > 0,05 sehingga H3 ditolak Penelitian ini menyatakan bahwa secara parsial variabel bebas NPM berpengaruh positif tidak signifikan terhadap Harga Saham. Hal ini terjadi dikarenakan NPM memiliki pengaruh yang kuat akan tetapi tidak mampu memberikan kontribusi yang signifikan terhadap naiknya harga saham. Laba yang dihasilkan oleh perusahaan kurang maksimal, sehingga hal tersebut mempengaruhi kinerja perusahaan, dan berdampak pada tidak signifikannya harga saham. Hasil penelitian ini sesuai dengan penelitian milik Ramadhana et al., (2018) dan tidak sejalan dengan penelitian milik Rahmat \& Dewi (2014), Pitriana (2017), Öztürk \& Karabulut (2017) serta Istiqomah \& Winarto (2017).

\section{Pengaruh CCC (Cash Conversion Cycle) terhadap Harga Saham}

Uji t menjelaskan bahwa nilai Prob. CCC adalah 0,0496 < 0,05 sehingga H4 diterima, sehingga secara parsial penelitian ini sejalan dengan penelitian milik Wiyono, (2017). Dimana di dalam penelitian tersebut, semakin cepat siklus pengkonversian kas pada suatu perusahaan, maka semakin tinggi harga saham suatu perusahaan tersebut dikarenakan kas berjalan secara lancar, profitabilitas naik dan harga saham juga ikut meningkat. Penelitian ini tidak sejalan dengan penelitian milik Mbawuni et al., (2016). Dimana hasil penelitian tersebut menyatakan bahwa CCC tidak memiliki pengaruh signifikan terhadap profitabiltias, sehingga tidak berpengaruh terhadap harga saham.

\section{Pengaruh Suku Bunga terhadap Harga Saham}

Penelitian ini menyatakan bahwa secara parsial variabel bebas suku bunga berpengaruh positif signifikan terhadap Harga Saham. Dapat dilihat bahwa uji t menjelaskan bahwa nilai probabilitas suku bunga adalah 0,0027 < 0,05 sehingga H5 ditolak, Hasil penelitian ini sesuai dengan penelitian milik Nurlina, (2017) dan Iba \& Wardhana, (2012). Suku bunga yang memiliki pengaruh positif signifikan terhadap harga saham dapat disebabkan oleh pihak Bank Indonesia yang memberikan kebijakan tertentu guna menyikapi lonjakan inflasi dan mempertahankan kurs. Selain itu, adanya teori high risk high return menyebabkan para investor menjadi tertarik dengan harga saham yang ditawarkan walaupun risiko yang akan diterima juga tinggi. Hasil penelitian tidak sesuai dengan penelitian milik Widiastuti et al., (2016) yang menyatakan bahwa variabel Suku bunga tidak berpengaruh signifikan terhadap harga saham secara parsial.

\section{Simpulan dan saran}

Penelitian bertujuan untuk menguji dampak faktor internal dan eksternal baik secara simultan maupun parsial terhadap harga saham sektor Infrastruktur, Utilitas, dan Transportasi periode 2014 2018 yang terdaftar di Bursa Efek Indonesia. Berdasarkan hasil analisis, maka simpulan yang dapat diambil adalah sebagai berikut (1) Terdapat pengaruh secara bersama-sama Dividend Payout Ratio (DPR), Net Profit Margin (NPM), Cash Conversion Cycle (CCC) dan suku bunga terhadap harga saham ; (2) Terdapat pengaruh positif tidak signifikan DPR terhadap harga saham ; (3) Terdapat pengaruh positif tidak signifikan NPM terhadap harga saham ; (4) Terdapat pengaruh negatif signifikan CCC terhadap harga saham ; (5) Terdapat pengaruh positif signifikan suku bunga terhadap harga saham. Dari hasil 
penelitian yang dilakukan, menunjukan bahwa harga saham dipengaruhi oleh variabel bebas DPR, NPM, CCC dan suku bunga. Hal ini dapat terjadi dikarenakan harga saham di suatu negara dipengaruhi tidak hanya oleh keadaan internal perusahaan di negara tersebut tetapi juga dari eksternal perusahaan yaitu suku bunga. Selain itu, laba yang dihasilkan oleh perusahaan kurang maksimal, sehingga hal tersebut mempengaruhi kinerja perusahaan dan dividen yang dibagikan, sehingga hal ini berdampak pada tidak signifikannya harga saham. Di sisi lain, CCC memiliki dampak terhadap harga saham yaitu semakin cepat siklus pengkonversian kas pada suatu perusahaan, maka semakin tinggi harga saham suatu perusahaan tersebut dikarenakan kas berjalan secara lancar, profitabilitas naik dan harga saham juga ikut meningkat. Sedangkan faktor suku bunga, memiliki pengaruh positif terhadap harga saham disebabkan oleh pihak Bank Indonesia yang memberikan kebijakan tertentu guna menyikapi lonjakan inflasi dan mempertahankan kurs. Selain itu, adanya teori high risk high return menyebabkan para investor menjadi tertarik dengan harga saham yang ditawarkan walaupun risiko yang akan diterima juga tinggi.

Penelitian ini memiliki keterbatasan yaitu data penelitian tidak terdistribusi normal, sehingga penelitian selanjutnya dapat memperbanyak jumlah pengamatan agar data penelitian yang digunakan bisa terdistribusi normal. Dari hasil penelitian, saran yang dapat digunakan adalah pertama, bagi para manajer perusahaan sektor infrastruktur, utilitas dan transportasi yang tercatat di BEI hendaknya mengembangkan harga saham dengan menjaga harga saham tetap stabil dengan cara mengawasi siklus kas pada perusahaan tersebut agar berjalan lancar dan para investor atau calon investor memiliki ketertarikan untuk menginvestasikan dananya pada perusahaan sektor infrastruktur, utilitas dan transportasi. Kedua, bagi para investor dan calon investor saat akan menginvestasikan saham, sebaiknya juga memperhatikan variabel makro ekonomi. Hal ini dikarenakan suku bunga acuan yaitu BI Rate pada hasil penelitian mempunyai pengaruh terhadap fluktuasi harga saham dan yang terakhir yaitu bagi para peneliti yang selanjutnya, diharapkan untuk menambah faktor - faktor variabel bebas yang lain, agar dapat menghasilkan hasil penelitian yang maksimal.

\section{Daftar Rujukan}

Agu, S. (2019). Effect Of Working Capital Management On The Profitability Of Nigerian Manufacturing Sector: Evidence From Nigerian Breweries Plc. EPRA International Journal of Multidisciplinary Research, 5(4).

Al Masum, A. (2014). Dividend Policy And Its Impact On Stock Price - A Study On Commercial Banks Listed In Dhaka Stock Exchange. Global Disclosure of Economics and Business, 3(1), 9-20.

Badan Koordinasi Penanaman, M. (2019). Investasi Langsung Dalam Negeri. Retrieved from https://www.bkpm.go.id/id/statistik/investasi-langsung-dalam-negeri-ddi

Baidarus, M., Nimas Ayu Anggraeni, C. D., \& Zafira Mauliza, H. (2018). Tinjauan Atas Regulasi Penanaman Modal Guna Meningkatkan Ketertarikan Investasi Infrastruktur Strategis Di Indonesia. Jurnal Badan Pendidikan Dan Pelatihan Keuangan Kementerian Keuangan Republik Indonesia, 11, 123-145. Retrieved from https://jurnal.bppk.kemenkeu.go.id/jurnalbppk/article/view/163

Bayrakdaroglu, A., Mirgen, C., \& Kuyu, E. (2017). Relationship Between Profitability Ratios and Stock Prices: an Empirical Analysis on Bist-100. Pressacademia, 6(1), 1-10. https://doi.org/10.17261/pressacademia.2017.737

Bhattacharya, S. (1979). Imperfect Information, Dividend Policy, and "the Bird in the Hand " Fallacy. The Bell Journal OfEconomics, 10(1), 259-270. https://doi.org/10.2469/dig.v27.n1.3

Girsang, A. N., Tambun, H. D., Putri, A., Rarasati, D., Nainggolan, D. S. S., \& Desi, P. (2019). Analisis Pengaruh EPS, DPR, dan DER terhadap Harga Saham Sektor Trade, Services, \& Investment di BEI. Jesya (Jurnal Ekonomi \& Ekonomi Syariah), 2(2), 351-362. https://doi.org/10.36778/jesya.v2i2.97

Gordon, M. J. (1963). Optimal Investment and Financing Policy. Journal of Finance, 40(4), 264-272. https://doi.org/https://doi.org/10.1111/j.1540-6261.1963.tb00722.x

Iba, Z., \& Wardhana, A. (2012). Perusahaan Pembiayaan Di Bursa Efek Indonesia. Jurnal Kebangsaan, 1(1), 1-6. Retrieved from https://zainiba.files.wordpress.com/2013/10/bursa-efek.pdf

Istiqomah, \& Winarto, H. (2017). Pengaruh Debt To Equity Ratio, Net Profit Margin Dan Earning Per Share 
Terhadap Harga Saham Pt Mandom Indonesia Tbk. Jurnal Manajemen Bisnis Krisnadwipayana, 5(3), 1-14. Retrieved from http://ojs.ekonomi-unkris.ac.id/index.php/JMBK/article/view/152/pdf

Kembaren, T., Achsani, N. A., Nur, T., \& Maulana, A. (2019). Dividend payout, internal and other external factors, and its impact on stock price. Jurnal Keuangan Dan Perbankan, 23(2), 235-245. https://doi.org/https://doi.org/ 10.26905/jkdp.v23i2.2520 |

Khan, K. I. (2012). Effect of Dividends on Stock Prices- A Case of Chemical and Pharmaceutical Industry of Pakistan. Management, 2(5), 141-148. https://doi.org/10.5923/j.mm.20120205.02

Lintner, J. (1962). Dividends, Earnings, Leverage, Stock Prices and the Supply of Capital to Corporations. The Review of Economic and Statistics, 44(3), 243-269. https://doi.org/https://doi.org/10.2307/1926397

Markowitz, H. M. (1952). Portfolio Selection. The Journal of The American Finance Association, 77-91. https://doi.org/https://doi.org/10.1111/j.1540-6261.1952.tb01525.x

Mbawuni, J., Mbawuni, M. H., \& Nimako, S. G. (2016). The Impact of Working Capital Management on Profitability of Petroleum Retail Firms: Empirical Evidence from Ghana. International Journal of Economics and Finance, 8(6), 49. https://doi.org/10.5539/ijef.v8n6p49

Nurlina. (2017). Pengaruh Nilai Tukar dan Suku Bunga Terhadap Harga Saham. 1(1), 33-41.

Nwaobia, A. N., Alu, C. N., \& Olurin, O., T. (2017). Dividend Payout Ratio and Share Price : Evidence from Quoted Manufacturing Companies in Nigeria. IOSR Journal of Business and Management, 19(10), 30 43. https://doi.org/10.9790/487X-1910093043

Öztürk, H., \& Karabulut, T. A. (2017). The Relationship Between Earnings-to-Price, Current Ratio, Profit Margin and Return: An Empirical Analysis on Istanbul Stock Exchange. Accounting and Finance Research, 7(1), 109. https://doi.org/10.5430/afr.v7n1p109

Pitriana, N. (2017). Pengaruh Net Profit Margin ( NPM ), Price Earning Ratio ( PER ) Dan Return On Equity ( Roe ) Terhadap Harga Saham Pada Perusahaan Food. EJournal Administrasi Bisnis, 5(2), 297-308

Rahmat, H., \& Dewi, sari puspita. (2014). Pengaruh Net Profit Margin dan Return on Assets Terhadap Harga Saham Pada Perusahaan Otomotif yang Terdapat di Bursa Efek Indonesia. 1(1), 1-10. Retrieved from https://www.researchgate.net/publication/281238449_Pengaruh_Net_Profit_Margin_dan_Return_ on_Assets_terhadap_Harga_Saham_pada_Perusahaan_Otomotif_yang_Terdaftar_di_Bursa_Efek_Indo nesia

Ramadhana, A. A., Sjahruddin, H., \& Hadi Purnomo, S. (2018). Pengaruh Kinerja Keuangan Terhadap Harga Saham. Jurnal Organisasi Dan Manajemen, (1), 47-65. Retrieved from https://www.researchgate.net/publication/327871411_Pengaruh_Kinerja_Keuangan_Terhadap_H arga_Saham

Ross, S. A. (1976). The arbitrage theory of capital asset pricing (Working Paper Version). Journal of Economic Theory, 13(3), 341-360. Retrieved from http://www.investmentanomalies.com/articles/031.pdf

Setyanto, A. D., \& Permatasari, I. (2015). Manajemen Modal Kerja Dan Dampaknya Terhadap Nilai Perusahaan Dengan Corporate Governance Sebagai Variabel Pemoderasi. Jurnal Akuntansi AKRUAL, (1), 66-82. Retrieved from http://fe.unesa.ac.id/ojs/index.php/akrl

Suchia, A. (2018). Pengaruh Kurs, Inflasi, Dan Suku Bunga Sbi Terhadap Indeks Harga Saham Idx30 Di Bursa Efek Indonesia. EJournal Administrasi Bisnis, 6(1), 201-213.

Wahyuni, S. F., \& Hafiz, M. S. (2016). Pengaruh CR, DER, dan EPS Terhadap DPR Pada Perusahaan Manufaktur. Jurnal Ekonomi Dan Ekonomi Syariah, 1(2), 31-48. 
Widiastuti, M., K, E. S., \& Dewi, C. K. (2016). Inflasi Terhadap Harga Saham Pada Pt Bank Central Asia Tbk Tahun 2012-2016. 1-10.

Wiyono, G. (2017). Efektifitas Manajemen Siklus Konversi Kas Perusahaan Sektor Aneka Usaha Terdaftar di BEI. EKUITAS (Jurnal Ekonomi Dan Keuangan), 1(4), 451. https://doi.org/10.24034/j25485024.y2017.v1.i4.2728 